\title{
ESTRÉS POR ACULTURACIÓN Y ESTRATEGIAS DE AFRONTAMIENTO EN UNA MUESTRA DE REFUGIADOS Y SOLICITANTES DE ASILO EN LIMA (PERÚ)
}

\section{ACCULTURATIVE STRESS AND COPING IN A SAMPLE OF REFUGEES AND ASYLUM SEEKERS IN LIMA (PERU)}

Patricia Cabrerizo*, Iciar Villacieros

Resumen: El objetivo de este estudio fue explorar los estresores y estrategias de afrontamiento asociados al proceso de aculturación de una muestra de refugiados y solicitantes de asilo en Lima, Perú. A través de la metodología cualitativa, se analizaron 22 entrevistas semi-estructuradas (11 varones y 11 mujeres) procedentes de Venezuela, Colombia y Cuba, entre otros. Los resultados revelan tres grupos de estresores: estrés por falta de derechos y condiciones de vida, dificultades para relacionarse con los locales en el país de destino y dificultades familiares. Las estrategias de afrontamiento fueron llevar una vida espiritual, pensar en el bienestar de su familia, creer en las propias capacidades, expresar emociones, buscar activamente soluciones y apoyo social. En conclusión, los estresores se presentaron en conjunto, retroalimentándose, lo que parece llevar al uso de diversas estrategias de afrontamiento.

Palabras clave: estrés por aculturación; afrontamiento; refugiados; solicitantes de asilo.

* Universidad Antonio Ruiz de Montoya (Lima-Perú) 
Abstract: The aim of this study was to explore migratory stressors and coping strategies linked to the process of acculturation in a sample of refugees and asylum seekers who were living in Lima (Peru). Through a qualitative methodology, 22 semi-structured interviews were analyzed (11 males and 11 females) from Venezuela, Colombia and Cuba, among others. As result, the main stressors were grouped in three themes: poor living conditions/rights, difficulties to interact with locals and family issues. The main coping strategies described were: spiritual life, thinking about the wellness of their families, believing on their own capabilities, expressing emotions and worries, actively searching for solutions and social support. In conclusion: refugees and asylum seekers experiment several stressors at the same time and develop different coping strategies in the adaptation process.

Key words: acculturative stress; coping; refugees; asylum seekers.

\section{INTRODUCCIÓN}

La cantidad de personas que migran de manera forzada ha aumentado en los últimos años (ACNUR, 2018; Urzúa, Basabe, Echeverry y Gibbons, 2017). A fines del 2017, había 68,5 millones de personas desplazadas forzosamente en todo el mundo, cifra que incluye a más de 25 millones de refugiados y 3 millones de solicitantes de asilo. Aunque gran parte de la atención internacional ha estado centrada en refugiados que llegan a Europa, esta problemática también afecta a otros continentes (ACNUR, 2018), así como a países de medianos y bajos recursos (Abubakar et al. 2018) o que solían ser países de emigrantes (Urzúa et al. 2017).

El Perú es uno de los países afectados por la migración forzada, ya que alberga 1.817 refugiados y 37.757 solicitantes de asilo de más de 30 nacionalidades de América Latina, África, Asia, Europa del Este y Medio Oriente (ACNUR, 2018). La cantidad de solitantes de asilo en el Perú ha crecido exponencialmente en los últimos años (ACNUR, 2016, 2017, 2018), convirtiéndose en uno de los países con la mayor cantidad de solicitudes de asilo en Latinoamérica (ACNUR, 2018).

Existe un marco legal que regula el otorgamiento y protección de los refugiados en el Perú (ACNUR, 2014; Ley del Refugiado. Ley 
Núm. 27891, 2002; Rubio, 2012), que considera como refugiado a toda persona que debe salir de su país de nacionalidad o residencia para acogerse a la protección de otro país, debido a:

(...) fundados temores de ser perseguida por motivos de raza, religión, nacionalidad, pertenencia a un determinado grupo social u opiniones políticas (...) o por causa de la violación masiva de los derechos humanos, agresión extranjera, conflicto interno, ocupación o dominación extranjera; o en razón de acontecimientos que perturben gravemente el orden público (Ley del Refugiado. Ley Núm. 27891, 2002, p. 1 y 2).

En este marco, los solicitantes de asilo son personas que presentan una solicitud para tener la condición de refugiado y son registrados como tales (Ley del Refugiado. Ley Núm. 27891, 2002).

Las personas que son forzadas a migrar a otros países, como los refugiados, tienen el riesgo de vivir niveles intensos de estrés (Achotegui, 2008), que pueden impactar negativamente en su salud (Médicos Sin Fronteras, 2016). Sin embargo, los estudios en el Perú se han centrado únicamente en las dinámicas migratorias en zonas fronterizas (Berganza, 2016) y características de refugiados (Sénier, 2014). Además, la mayoría de estudios sobre estrés se centra únicamente en los efectos de experiencias traumáticas y sus consecuencias psicológicas, más que en las respuestas frente a la adversidad (Puvimanasinghe, Denson, Augoustinos y Somasundaram, 2014). Asimismo, muchos estudios sobre el tema se realizaron únicamente con poblaciones de refugiados en Europa o Estados Unidos (Ai, Tice, Whitsett y Ishisaka, 2007; Bentley et al., 2014; Finch y Vega, 2003; Puvimanasinghe et al. 2014; Rae, 2016) y existe limitada información acerca de poblaciones migrantes latinas (Zarza y Sobrino, 2007).

Ante todo lo expuesto, el objetivo de este estudio es analizar los estresores vividos por refugiados y solicitantes de asilo asentados en Lima (Perú) y sus estrategias de afrontamiento; respondiendo a la necesidad de generar mayor evidencia cualitativa sobre sus experiencias en el proceso de aculturación (Zlobina, Bassabe y Páez, 2008), que puedan ser aplicadas a acciones de atención y prevención (Zarza y Sobrino, 2007). 


\section{ANTECEDENTES}

\subsection{El estrés por aculturación}

El impacto del estrés se hace evidente en cada una de las fases de la migración: antes de migrar, durante el trayecto y en el país de destino (Haagen et al., 2017). Según el informe de Médicos Sin Fronteras (2016), además de los traumas vividos en el país de origen como la violencia o persecución, los propios viajes migratorios conllevan riesgos y un alto grado de estrés atribuidos al propio exilio y llegada a un país desconocido. Cada uno de los hechos adversos sufridos tienen un efecto acumulativo en la salud física y mental de las personas forzadas a migrar (Bhruga, 2004; Finch y Vega, 2003; Hovey y King, 1996; Médicos Sin Fronteras, 2016).

En el país de destino, se da el estrés por aculturación, también llamado cultural shock (Furnham y Bochner, 1986), que hace referencia a la respuesta de estrés frente a las experiencias de adaptación (Berry, 2005). Estas experiencias pueden implicar demandas para el sujeto superiores a sus capacidades o recursos psicológicos (Bhugra, 2004). Las dificultades aumentan cuando hay mayores diferencias culturales (Ward y Kennedy, 1999), aunque hay evidencia de que el estrés por aculturación se produce también en la adaptación a países con características económicas, sociales o culturales similares a las del país de origen (Zarza y Sobrino, 2007).

En este proceso existen diversos estresores (Bonnano, 2010), definidos como situaciones o eventos que son evaluados por la persona como una amenaza para su bienestar físico o psicológico (Gunnar y Quevedo, 2007). En el caso de la migración forzada, los estresores pueden ser de mayor intensidad y duración, presentarse en conjunto y/o estar fuera del control de las personas, lo que se asocia a mayores síntomas de ansiedad o depresión (Achotegui, 2008)

Cada experiencia de aculturación es distinta (Berry, 2005), pudiendo variar por características personales, culturales o de la experiencia de adaptación (De Luca, Bobowik y Basabe. 2011; De Luca y Telletxea, 2017; Urzúa, Basabe, Pizarro y Ferrer, 2017; Zlobina et al., 2008). Sin embargo, hay estudios con población refugiada que han encontrado estresores similares, los que se pueden organizar en cuatro grupos: a) Estresores por las condiciones de vida, como las dificultades en la búsqueda de empleo, las condiciones de precariedad laboral (Cabrerizo y Villacieros, 2017; CCPM, Migraciones y Acnur, 
2013; Morrison, 2016; Seglem et al., 2014; Torres et al. 2017), los problemas económicos (CCPM, Migraciones y Acnur, 2013; Médicos Sin Fronteras, 2016; Seglem et al., 2014), el escaso acceso a los servicios de salud, educación y crédito (Cabrerizo y Villacieros, 2017; CCPM, Migraciones y Acnur, 2013), o las dificultades para tener una vivienda digna y segura (Achotegui, 2008; CCPM, Migraciones y Acnur, 2013); b) Estresores asociados a la documentación y ciudadanía: la falta de documentación o poca aceptación de esta (Achotegui, 2008; Haagen, et al., 2017), el estatus legal como migrante (Finch y Vega, 2003; Torres et al., 2017) y las dificultades para pasar de "refugiado" a "ciudadano" (Puvimanasinghe et al., 2014); c) Estresores de adaptación al nuevo grupo: el aislamiento debido a las dificultades para adaptarse a una nueva ciudad, las costumbres y/o idioma del país de destino (Medicos Sin Fronteras, 2016; Puvimanasinghe et al., 2014; Villacieros, Berástegui y Aza, 2016) o la discriminación por motivos de raza, origen o nacionalidad o la estigmatización (Bencek y Strasheim, 2016; Cabrerizo y Villacieros, 2017; Finch, Hummer, Kolody y Vega, 2001; Finch y Vega, 2003; Urzúa et al., 2017); d) Estresores personales: El sentimiento de inseguridad y miedo en el país de destino (Achotegui, 2008), la incertidumbre por las desigualdades sufridas cotidianamente (Morrison, 2016) o la ruptura de la familia y separación de seres queridos debido a la migración (Achotegui, 2008; Medicos Sin Fronteras, 2016; Puvimanasinghe et al., 2014; Rae, 2016; Urzúa et al., 2017).

\subsection{El afrontamiento}

Frente a las condiciones de vida estresantes en el proceso de aculturación, las personas utilizan una serie de estrategias de afrontamiento (Bentley, Ahmad y Thoburn, 2014; Bhugra, 2004; Clarke y Border, 2014; Puvimanasinghe et al, 2014). Estas estrategias son procesos de carácter interactivo, que permiten a los sujetos desenvolverse ante diferentes situaciones estresantes, activando múltiples procesos fisiológicos, emocionales, comportamentales, motivacionales, atencionales e interpersonales (Skinner y Zimmer-Gembeck, 2007). Así, el concepto afrontamiento supone un proceso personal de valoración y respuesta ante situaciones estresantes (Lazarus y Folkman, 1986). Este modelo ha sido comprobado en numerosas muestras y situaciones, demostrando su viabilidad (Cano, Rodríguez y García, 2007). 
Las estrategias de afrontamiento en población refugiada o similar más comunmente encontradas en la investigación son: el apoyo familiar, social o comunitario (Aref y Tummala-Narra, 2015; Finklestein, Laufer y Solomon, 2012; Goodman, 2004; Guribye, 2011; Huijts, et al., 2012; Hovey, 1999; Puvimanasinghe et al., 2014; Renner, Laireiter y Maier, 2012; Torres et al., 2017); la religiosidad, la vida espiritual, rezar (Bentley et al., 2014; Finklestein at al., 2012; Goodman, 2004; Puvimanasinghe et al., 2014; Torres et al., 2017); los procesos cognitivos, como la evitación o los esfuerzos para detener pensamientos no deseados (Goodman, 2004), dar un significado al hecho traumático (Puvimanasinghe et al, 2014), valorar las propias capacidades para afrontar la adversidad (Ai et al., 2007; Clarke y Border, 2014; Rae, 2016) o su situación migratoria (Urzúa et al., 2017); el altruismo, la colaboración o ayuda a otros (Huijts et al., 2012; Puvimanasinghe et al., 2014); la búsqueda activa de soluciones a las dificultades de la migración (Huits et al., 2012; Tobin et al., 1989 en Cano et al., 2007; Villacieros, Berástegui y Aza, 2016; Walsh, 2004); la búsqueda de ayuda profesional (Clarke y Border, 2014; Horyniak, Higgs, Cogger, Dietze y Bofu, 2016); hablar o expresarse sobre las situaciones que viven (Boucher, 2009); adoptar actitudes positivas de la cultura de destino o comprometerse con el nuevo entorno (Clarke y Border, 2014); y la distracción (Urzúa et al., 2017).

\section{METODOLOGÍA}

Con la finalidad de entender cuáles eran los estresores y estrategias de afrontamiento asociados al proceso de aculturación, se realizó un estudio cualitativo con enfoque fenomenológico (Hernández, Fernández-Collado y Baptista, 2014). Se realizaron entrevistas semiestructuradas a 22 personas (11 varones y 11 mujeres) residentes en Lima, Perú. Del total de participantes, 17 eran refugiados y 5 solicitantes de asilo. Respecto a su lugar de origen, 9 eran de Venezuela, 7 de Colombia, 2 de Cuba, 2 de República Dominicana, una de Haití y una participante de El Salvador. El tiempo de residencia de los participantes en el Perú fue heterogénero; 5 personas residían en el país por un tiempo menor a un año, 9 personas tenían entre 1 año y 3 años de residencia, mientras que 8 personas estaban en el Perú hacía más de 4 años. 
Se consideraron tres criterios de inclusión para participar en el estudio. En primer lugar, se seleccionó a personas registradas como refugiadas o solicitantes de asilo, es decir, personas que se encontraban en un proceso de evaluación para ser refugiadas. En segundo lugar, se incluyó a personas provenientes de países distintos al Perú en los que se hable español como primera lengua, a fin de garantizar la viabilidad, ya que las entrevistas fueron realizadas por entrevistadoras hispanohablantes. En tercer lugar, se consideraron solo aquellas personas mayores de 18 años que residían en Lima. Los criterios de exclusión fueron: haber renunciado a la condición de refugiado, haber recibido una respuesta negativa a la solicitud de asilo y residir en una ciudad distinta a Lima.

La selección de participantes se hizo en coordinación con una organización no gubernamental, ubicada en Lima Metropolitana, que realiza acciones de apoyo a refugiados y solicitantes de asilo. Además, se buscó seleccionar a un grupo diverso de personas por nacionalidad, tiempo de residencia y condición migratoria (refugiados y solicitantes de asilo). Sin embargo, se incluyó a un grupo mayor de personas de Colombia y Venezuela, ya que ambos representaban la mayor parte de personas en la lista. En total, se contactó a aproximadamente a 50 personas por teléfono para solicitar su participación en el estudio, pero solo 22 aceptaron participar.

Las entrevistas se realizaron entre marzo y julio del 2016, en un espacio privado dentro del local la organización colaboradora, y tuvieron una duración aproximada de 50 minutos. Las preguntas de las entrevistas incluyeron información sobre datos sociodemográficos de los participantes ${ }^{1}$, condiciones y estresores en el viaje migratorio, estresores asociados al proceso de aculturación ${ }^{2}$, síntomas de estrés $^{3}$ y estrategias de afrontamiento ${ }^{4}$. Los participantes firmaron un consentimiento informado, en el cual permitían el uso de su información para los fines de la investigación, así como la grabación de las entrevistas. No se registraron nombres a fin de respetar la privacidad de los participantes.

1 Como edad, sexo, país de nacimiento, tiempo de estadía en el Perú y lugar de residencia.

2 Pregunta base: Desde que llegó a Perú, ¿Qué situaciones le generan estrés o incomodidad?

3 Pregunta base: ¿Cuáles son los principales sentimientos que ha experimentado?

4 Presegunda base: Cuando le pasó (nombrar estresor)

¿Qué hizo o pensó? (pregunta por cada estresor) 
La información de las entrevistas fue transcrita y separada por ejes temáticos en función a las variables del estudio. Se realizó un análisis de contenido a fin identificar categorías comunes (Flick, 2015), utilizando un enfoque émico para comprender las estructuras de las variables a partir de la percepción de los entrevistados en el contexto en que ocurren (Poortinga, 1997). Así, se generaron y ordenaron categorías partiendo del discurso de los participantes, que fueron revisadas en distintos periodos por ambas investigadoras para buscar mayor fiabilidad. Se ordenaron las categorías de acuerdo a su recurrencia en el discurso de los participantes, sin embargo no se cuantificó la información ya que, considerando el enfoque de investigación, el análisis se centró en comprender el contenido de las categorías desde la perspectiva de los participantes (Hsieh y Shannon, 2005). El artículo se centra en el análisis de los estresores y estrategias de afrontamiento asociadas al proceso de aculturación.

\section{RESULTADOS}

\subsection{Estresores asociados al proceso de aculturación}

El análisis de resultados acerca de los estresores mostró quince categorías de estresores que hacen referencia a tres tipos de problemáticas asociadas al proceso de aculturación de refugiados y solicitantes de asilo en Perú: a) vulneración de derechos y condiciones de vida, b) dificultades para relacionarse con personas del país receptor y c) dificultades familiares. A continuación, se hace una descripción de cada eje y sus categorías que fueron producto del análisis de contenido.

\subsubsection{Estresores asociados a la vulneración de derechos y condiciones de vida}

Los principales estresores identificados por los entrevistados estaban relacionados a dificultades para al acceso a empleo y vivienda con condiciones adecuadas, contar con ingresos suficientes para mantener su hogar y acceder a servicios de salud y educación. 
Acceso a trabajo y condiciones laborales

La falta de acceso a trabajo, por tiempo prolongado, es uno de los estresores comúnmente mencionados tanto por refugiados como solicitantes de asilo. Según los entrevistados, la dificultad para conseguir empleo se debe a dos razones: la poca aceptación de la documentación y la falta de contactos. En cuanto a la documentación, los entrevistados señalan que muchas organizaciones se niegan a contratar personas con documentación de refugiado o solicitante, aunque esta esté al día y sea válida para conseguir empleo de acuerdo a la ley peruana.

"Ah, porque yo llegaba a las empresas a buscar trabajo y cuando ya sabian de que yo no tenía documentos ya me decían que no y me decían que primero los peruanos y después la demás gente?..." (Refugiado, El Salvador)

La falta de aceptación de la documentación de refugiados para tener un empleo se complejiza cuando se requiere la realización de otros trámites asociados al contrato laboral, como la renovación de documentación migratoria, cuyo proceso puede ser confuso, generando mayor incomodidad en los entrevistados.

“....era bien frustrante porque... el carnet de extranjería está de la mano con el contrato de trabajo... entonces no se sabe qué es primero si el contrato de trabajo o el carnet de extranjería?" (Refugiado, Venezuela)

Además de las dificultades con la documentación, los refugiados y solicitantes de asilo señalaron que otro obstáculo importante para conseguir empleo es la falta de contactos locales por ser extranjero.

“...tú vas a un sitio, te ofrecen, ofreces lo que sabes y entonces prácticamente no te toman en cuenta porque tiene que venir alguien que te diga, mira yo lo conozco, él trabajó conmigo, él es bueno haciendo esto y ahí sí está dan la oportunidad." (Refugiado, Venezuela)

En el caso de los entrevistados que lograron conseguir un empleo, las situaciones que generaron estrés se refieren a las condiciones laborales inadecuadas. Así, los entrevistados resaltaron la incomodidad por trabajar en espacios informales, con remuneraciones muy 
reducidas, riesgos de daño y exceso de horas a las permitidas legalmente.

“... yo decía dios mío de ganar 80 a 100 soles (En Colombia) a ganar 30 soles? De 5 am a 11 pm?? Porque un señor me dice, yo le voy a dar trabajo a usted que me parece que es una persona buena, si sabe, le pago 40 soles, sino sabe le pago 30." (Refugiado, Colombia)

Ingresos insuficientes

Los participantes identificaron que no contar con ingresos suficientes también es un estresor, ya que no permite cubrir los gastos para el mantenimiento de su hogar. De acuerdo con los entrevistados, los bajos ingresos estan relacionados a la dificultad para acceder a un empleo o la baja remuneración. Esta situación se vuelve crítica en el caso de entrevistados que cuentan con una familia, ya que no logran cubrir las necesidades básicas de sus familiares.

"... como les digo que no hay comida? bueno tómense un vaso de agua, nos ha pasado: hay que tomar un vaso de agua mija linda porque hoy lamentablemente no hay pal pan... porque nos ha pasado, hubieron días que nos pasó, que no teníamos ni siquiera para el pan...". (Refugiada, Venezuela)

\section{Vivienda en condiciones inadecuadas}

Otra dificultad resaltante fue la imposibilidad de acceder a viviendas con condiciones adecuadas. Se mencionaron diferentes problemas, como la falta de espacios privados, el tamaño reducido de los espacios y la ausencia de servicios básicos. Esto fue resaltado especialmente por aquellas personas que tienen familia, y parece estar asociado a sus bajos ingresos que son insuficientes para acceder a una vivienda en mejores condiciones.

"Estamos viviendo en un cuarto súper deprimente, no tenemos privacidad, el ruido es increíble, se escucha todo, el baño es afuera compartido." (Solicitante de asilo, Venezuela)

Limitado acceso a servicios de educación y salud

Además se encontró que muchos de los entrevistados y sus familias no logran acceder a servicios de educación y salud. Los 
entrevistados relacionaron la dificultad de acceso a seguros de salud y servicios educativos estatales para sus hijos con la falta de aceptación de su documentación. En consecuencia, se ven obligados a pagar por aquellos servicios que necesitan con urgencia, lo que aumenta sus dificultades económicas.

"No me dan salud peruana que es el SIS (Seguro Integral de Salud), por eso no tengo el SIS. Entonces la verdad, en este tiempo que he estado en el país la salud me ha salido muy costosa acá, todo ha sido particular, la droga ha sido particular, no tengo ninguna ayuda por ningún lado de la salud..." (Refugiado, Colombia)

\subsubsection{Dificultades para relacionarse con personas del país receptor}

Existen otros tipos de estresores que se refieren a la relación con las personas locales del país receptor. los entrevistados señalaron cuatro tipos de situaciones: las dificultades para adaptarse a costumbres locales, discriminación y rechazo, inseguridad y delincuencia, y maltrato por parte de la policía.

\section{Dificultades para adaptarse a costumbres locales}

Las dificultades para adaptarse a costumbres locales se refieren a los obstáculos para lograr comprender y adaptarse al lenguaje y las costumbres en las interacciones sociales. En cuanto al lenguaje, los entrevistados mencionaron tener dificultades para entender el significado de palabras o frases comúnmente utilizadas por peruanos, aún cuando comparten el mismo lenguaje. También se resaltaron las dificultades para adaptarse a las costumbres de interacción en espacios públicos, los relacionados a la falta de saludo, insultos, la impuntualidad y otros comportamientos ajenos a los "buenos modales".

"O que vayas caminando por la calle y te tropiecen y en vez de pedirte disculpas más bien te reclamen o te insulten o te griten..." (Refugiado, Venezuela)

Además, mencionaron tener dificultades para comprender las costumbres en espacios laborales, especialmente aquellas relacionadas al alto nivel de competencia y falta de solidaridad entre las personas. 
"Yo vendía tallarín, ahora la señora quiere vender tallarín, o sea eso me parece envidioso porque si yo veo que la señora está vendiendo su gaseosita con sus golosinas y todo lo que vende y su canchita y todo, sería yo una egoísta al poner al frente un puesto de eso". (Refugiada, Colombia)

Este estresor, les supuso un obstáculo para interactuar de manera positiva con personas locales en espacios laborales o públicos, especialmente durante los primeros meses de establecimiento en el Perú.

\section{Discriminación y rechazo}

En segundo lugar, los entrevistados mencionaron haberse sentido discriminados por personas peruanas en distintas situaciones de trabajo, en la realización de trámites burocráticos o compras, debido a su forma de hablar o nacionalidad. Este rechazo fue identificado principalmente por personas de Colombia, quienes señalaron la existencia de estereotipos que asocian la nacionalidad colombiana con actividades de narcotráfico, delincuencia y prostitución, como se puede observar en el siguiente testimonio:

"... a uno le escuchan el dejo diferente entonces dicen "ah colombiano! Ah! entonces éste es narcotraficante, este es sicario", mejor dicho todo nada bueno y si vamos con mi mujer... ah entonces también debe ser que también es prostituta que es..." (Refugiado, Colombia)

\section{Inseguridad y delincuencia}

En tercer lugar, algunos entrevistados mencionaron que ellos o algún miembro de su familia habían sido víctimas de robos u otros actos delictivos. Estas experiencias, sumadas a las noticias asociadas a la delincuencia, conforman la percepción de altos niveles de inseguridad como un estresor importante.

"A mi esposa... una chica y un chico le pusieron un revolver acá y le quitaron su celular..., que incluso eso me tocó llevarla con el psicólogo porque ella nunca había pasado por esas experiencias, nunca. Entonces eso también a mí me mantiene intranquilo, inseguro acá en el país." (Refugiado, Colombia) 
Maltrato de la policía

Por último, el trato por parte de la policía fue identificado como un estresor; ya que, algunos entrevistados reportaron experiencias de rechazo y maltrato. En algunos casos, se percibió que el maltrato de la policía se debía a la nacionalidad, al ser refugiado, así como al desconocimiento de sus derechos.

"Hace poquito nos pidieron (la policía) el carnet de extranjería y decían —no, ese carnet de extranjería está vencido,... Uds. no son, los vamos a deportar - ... y yo - pero ¿por qué? Si somos residentes refugiados, ¿Uds. saben qué son refugiados?_, —No, a mí no me importa esa palabra.--" (Refugiado, Colombia)

Si bien este estresor podría ser incluido en la categoría de rechazo y discriminación, se tomó la decisión de darle un espacio específico debido al alto riesgo que implica, de acuerdo a algunos entrevistados.

\subsubsection{Dificultades familiares}

Otro grupo de estresores identificados por los entrevistados se refieren a dificultades relacionadas a la familia, las cuales incluyen la preocupación por el bienestar de algún miembro de la familia o la separación de familia y amigos debido a la migración.

\section{Preocupación por familiares}

De acuerdo a las entrevistas, un estresor importante se refiere a la preocupación por conflictos al interior de la familia o dificultades de algunos de sus miembros relacionadas a salud física, mental, abuso de drogas, violencia, etc. Estas dificultades se presentan tanto en familiares que están en el país de origen, como en familiares que migraron junto con la persona entrevistada.

"Nos ha tocado situaciones difíciles de que hemos pasado 5 u 8 días sin saber nade él (mi hijo) y cuando nos damos cuenta es porque estaba por allá en un parque tirado, drogado, sucio, sin comer..." (Refugiada, Colombia) 
Separación de familia y amigos

Finalmente, algunos refugiados y solicitantes de asilo entrevistados señalaron que la separación de familia y amigos debido a la migración es un estresor durante su proceso de adaptación en el Perú. Esta percepción de separación parece estar relacionada no solo con la imposibilidad de reunirse nuevamente con su familia y amigos en un tiempo cercano, sino también con la sensación de estar solo(a) en un nuevo país, sin contar con redes de apoyo cercanas.

"De sentirte sola, yo estaba acostumbrada a estar con mi familia con mi hija, y que tu vienes a un país que no conoce a nadie para enfrentarte a todo, es bien difícil." (Refugiada, República Dominicana)

\subsection{Estrategias de afrontamiento utilizados en el proceso de aculturación}

Los refugiados y solicitantes de asilo entrevistados identificaron siete mecanismos principales de afrontamiento que utilizan para hacer frente a los estresores mencionados: llevar una vida espiritual, pedir ayuda a Dios, pensar en el bienestar de su familia, buscar activamente soluciones, evitar problemas, creer en uno mismo, expresar las emociones y buscar apoyo social.

\section{Vida espiritual}

Uno de los mecanismos de afrontamiento más comunmente mencionados en las entrevistas es la vida espiritual, que está reflejada en diferentes costumbres, como rezar y pedir a Dios mayor tranquilidad, guía, la mejora en las condiciones de vida, entre otros.

"Sí, le pedía mucho a dios que me dieran serenidad, me ayudara, me guiara que si mi destino y mi vida iban a hacer aquí en Perú, que guiara mis pasos; nunca perdí la fe en dios". (Refugiada, Venezuela)

Pensar en el bienestar de su familia

Un segundo mecanismo identificado por los entrevistados es pensar en el bienestar de la familia. Tanto refugiados como solicitantes 
de asilo señalaron que en diversas situaciones estresantes, pensaban en formas para lograr que los miembros de su familia mejoren sus condiciones de vida, cumplan sus metas o no repitan situaciones difíciles que los entrevistados vivieron.

"Pensar en mi familia, recordar que ellos me están esperando allá y que no puedo llegar de la misma manera a como me fui...que tengo que llegar para ayudarlos a ellos." (Solicitante de asilo, Venezuela)

Analizar y buscar soluciones activamente

Un tercer mecanismo mencionado se refiere a la búsqueda activa de soluciones, que incluye el análisis de la situación y la ejecución de acciones para solucionar diferentes dificultades, aunque es mencionado especialmente frente a estresores relacionados a las condiciones de vida, como la búsqueda de trabajo, la generación de mayores ingresos y el acceso a servicios básicos. Estas acciones son variadas y dependen de la situación que se busca afrontar.

"Buscar, buscar, buscar, buscar alternativas, buscar, buscar preguntar, hablar con todo el mundo, metete por aquí, métete por allá... hablar, hablar, preguntar quién me daba contrato de trabajo?... preguntar... hablar con todo el mundo." (Refugiado, Venezuela)

\section{Evitar problemas}

Evitar problemas es un mecanismo mencionado por varias personas, que incluye el "aguantar" o "no hacer nada" frente a dificultades, como una ayuda para evitar mayor estrés o problemas más complejos. Esta estrategia se presenta, asociada a dificultades en las relaciones personales, tanto con la familia como con personas del país receptor, o cuando sufren discriminación o rechazo.

"Ahhh qué he hecho? Aguantarme ya cuando ya uno los entiende, aguantarme la ira... No pues nada, quedarme callado" (Refugiado, Colombia).

Creer en las propias capacidades para salir adelante

Algunos participantes señalaron que creer en las propias capacidades para salir adelante fue un mecanismo de afrontamiento ante 
el estrés. Así, mencionaron que confiar en sus propias fuerzas para hacer frente a situaciones difíciles y darse ánimos es un mecanismo que utilizan recurrentemente. Estos elementos constituyen pensamientos positivos acerca de la capacidad de la persona para enfrentar distintas situaciones.

"Hay veces como le digo...me dan deseos como de flaqueas y de ahí yo misma me digo "no...", o sea yo misma me aconsejo, me... y de ahí sigo pa lante" (Refugiada, Cuba)

Búsqueda de apoyo social

Los entrevistados también señalaron que buscan apoyo social para enfrentar distintas situaciones. La búsqueda de apoyo de distinto tipo - como económico o emocional-, parece centrarse en la familia, amigos y migrantes del mismo país, aunque también se busca en instituciones de apoyo a refugiados.

“...el secreto del éxito de un inmigrante es tratar con otro inmigrante, tratar... y entre todos tratar de ayudarse, o sea nunca estar solo, siempre tratar de relacionarte con tu mismo, tu misma raza, tus mismos paisanos pero no todo el tiempo entre todos darse apoyo." (Refugiada, Venezuela)

\section{Expresar sus emociones y comunicarse}

Finalmente, la expresión y comunicación de emociones y pensamientos es uno de los mecanismos identificado en las entrevistas. Este mecanismo incluye acciones como hablar o expresar emociones de manera no verbal y se da sobre todo en las interacciones entre miembros de una misma familia o amigos.

"Al principio llamaba a mi mamá y lloro... Mi papá y lloro. Lloro con ellos." (Solicitante, Colombia)

\section{DISCUSION}

Los principales estresores identificados tienen que ver con las condiciones de vida, como el acceso a empleo, una vivienda adecuada y servicios básicos. La presencia de estos estresores indica que 
refugiados y solicitantes de asilo tienen muchas dificultades para cubrir sus necesidades básicas y contar con los derechos mínimos que se les asigna en acuerdos internacionales (CCPM, Migraciones y Acnur, 2013) y por ley peruana (Ley del Refugiado. Ley Núm. 27891, 2002).

En especial destaca la dificultad para conseguir un empleo y contar con condiciones laborales adecuadas. Esta dificultad se debe al estigma que conlleva tener un documento de refugiado y solicitantes de asilo, así como a la discriminación en ámbitos laborales, lo que dificulta el acceso al empleo (CCPM, Migraciones y Acnur, 2013; Cabrerizo y Villacieros, 2017). Es necesario considerar que la falta de acceso a empleo implica una pérdida de rol profesional, además de dificultades para garantizar condiciones de vida básicas, aumentando los niveles de estrés (Zarza y Sobrino, 2007). Además, las condiciones laborales inadecuadas, señaladas tambien en estudios con muestras similares, pueden tener impactos negativos en las condiciones de vida y salud de las personas (Seglem et al., 2014; Morrison, 2016; Torres et al., 2017).

La falta de empleo o bajos ingresos parecen llevar a problemas económinos en el país de destino, que representan una dificultad común en este estudio y otras investigaciones (CCPM, Migraciones y Acnur, 2013; Medicos Sin Fronteras, 2016; Seglem et al., 2014). Tal y como se ha encontrado en otros estudios en Perú, las dificultades económicas se asocian al acceso a viviendas precarias (CCPM, Migraciones y Acnur, 2013). Ambos elementos son factores que aumentan la tensión y síntomas de estrés (Achotegui, 2008).

Los entrevistados también resaltaron el acceso limitado a servicios debido a la falta de aceptación de su documentación, tal y como se confirma en otros estudios previos (Cabrerizo y Villacieros, 2017; CCPM, Migraciones y Acnur, 2013). El acceso a servicios es una dificultad que el estado peruano ha querido promover como parte de la integración de refugiados y solicitantes de asilo, tal y como se aprecia en la Ley del Refugiado (Ley Núm. 27891), pero sigue siendo un tema pendiente. Una posible explicación es el desconocimiento por parte de los operadores locales de servicios acerca de los derechos de refugiados y solicitantes, así como de la validez de su documentación. Así, se estaría reforzando la idea de que no son "ciudadanos" (Puvimanasinghe et al., 2014), con una documentación válida y todos los derechos que esto conlleva.

Además de las dificultades mencionadas, se identificaron obstáculos para adaptarse a las costumbres locales, como el uso del lenguaje 
y comportamientos en la interacción, especialmente en las primeras semanas de estadía. La adaptación a las costumbres locales también ha sido destacada en otras muestras similares como una dificultad en el proceso de integración en el país de destino (Medicos Sin Fronteras, 2016; Puvimanasinghe et al, 2014). Estas dificultades no solo afectan a personas con características distintas a las del país receptor (Puvimanasinghe et al., 2014), si no también a personas que comparten la misma lengua (Zarza y Sobrino, 2007; Villacieros, Berástegui y Aza, 2016) y características culturales similares a las del país receptor (Zarza y Sobrino, 2007), como es el caso de los participantes de este estudio.

Por otro lado, se reportaron situaciones discriminatorias, mostrando que la discriminación sigue siendo un problema para la adaptación de diferentes poblaciones de refugiados (Bencek y Strasheim, 2016; Cabrerizo y Villacieros, 2017; Finch y Vega, 2003; Urzúa et al., 2017), independientemente de su país de origen (Finch, et al, 2001). Sin embargo, solo en este estresor se observaron diferencias por nacionalidad. Esto puede confirmar la existencia de grupos que sufren una mayor estigmatización, como es el caso de personas colombianas, lo que según De Luca et al. (2011), podría deberse a la imagen de Colombia asociada a violencia y crímenes, transmitida en medios masivos. Es necesario considerar que la discriminación está asociada a mayores dificultades en la adaptación y síntomas de estrés (De Luca et al., 2011; Torres, et al. 2017), por lo que se necesitan generar estrategias para reportarla (Bencek y Strasheim, 2016) y reducirla (Abubakar et al, 2018).

También se identificó la inseguridad y delincuencia como un estresor, que podría deberse al contexto propio de ciudades urbanas en Perú, como Lima Metropolitana, en las que se existen altos niveles de delincuencia (INEI, 2017). Además, el acceso a viviendas sin mayor privacidad o en zonas de mayor delincuencia puede aumentar la sensación de inseguridad en este grupo.

Sumado a esto, se mencionaron situaciones de maltrato por parte de la policía. Si bien este estresor podría ser incluido en la categoría de discriminación y rechazo, se tomó la decisión de darle un espacio específico a fin de resaltar el hecho de que la entidad que debiera garantizar la seguridad se convierte en un riesgo, aumentando la sensación de inseguridad y vulnerabilidad la población refugiada. Esto parece indicar el desconocimiento de personal de la policía acerca de la condición de refugiado y solicitante de asilo, así como sus derechos. 
Por último, se identificaron estresores asociados a dificultades familiares y separación de la familia y amigos como parte de la migración. La separación de seres queridos es uno de los principales estresores identificados en estudios con otras muestras de refugiados (Medicos Sin Fronteras, 2016; Puvimanasinghe et al., 2014; Rae, 2016; Urzúa et al., 2017). Esta separación forzada puede llevar a procesos de duelo, asociados a soledad, tristeza y miedo, especialmente si se trata de la separación de la familia más cercana (Achotegui, 2008).

Todos estos elementos muestran que en el proceso de aculturación en contextos de migración forzada, existen diversos estresores que se presentan en conjunto, y corresponden a situaciones complejas que estan fuera de control, (Achotegui, 2008), como la discriminación y el rechazo de la población local. La suma de estas situaciones adversas generaría un efecto acumulativo que puede aumentar la vulnerabilidad social y psicológica de estas poblaciones, haciendo más difícil el afrontamiento (Bonnano, 2010).

Muchos de estos estresores no solo se presentan en conjunto, si no que pueden retroalimentarse. Este es el caso de las dificultades para tener un empleo con condiciones básicas o acceso a servicios debido a la documentación de refugiados. Una posible hipótesis encontrada en este estudio, es que existe una relación entre el acceso al empleo de la población refugiada y la discriminación; no solo por su nacionalidad, si no también por su estatuto de refugiado y la documentación asociada a esta condición. Así, este estudio parece mostrar una paradoja: el estatuto que habilita a refugiados y solicitantes de asilo como ciudadanos con derechos, al mismo tiempo, parece colocarlos como ciudadanos de segunda categoría, excluyéndolos y generando barreras para el acceso a derechos fundamentales. Esta exclusión podría llevar a que refugiados y solicitantes de asilo no se sientan ciudadanos con acceso a derechos en el país receptor, dificultando su proceso de adaptación.

Frente a los estresores mencionados se utilizaron diversas estrategias de afrontamiento. Algunas de estas estrategias — como la búsqueda de apoyo social, la vida espiritual y la expresión de emociones- se encuentran en hallazgos de investigaciones previas (Aref y Tummala-Narra 2015; Bentley et al., 2014; Finklestein et al., 2012; Goodman, 2004; Guribye, 2011; Huijts, et al., 2012; Hovey, 1999; Puvimanasinghe et al., 2014; Renner et al., 2012; Torres et al. 2017), indicando que poblaciones refugiadas en diferentes contextos pueden hacer uso de estrategias similares. 
Una de las principales estrategias utilizada por los entrevistados es la vida espiritual. Este mecanismo, se encuentra en otras investigaciones con población similar como estrategia de afrontamiento ante el estrés (Aref y Tummala-Narra, 2015), y pareciera cobrar importancia en momentos de preocupación o desesperanza frente a las dificultades que enfrentan (Goodman, 2004; Puvimanasinghe et al., 2014; Bentley et al., 2014). La importancia se debe a que el contacto espiritual de manera individual y la asistencia a actividades religiosas grupales ayudan dar un sentido a problemas o eventos traumáticos y son consideradas como una fuente a apoyo frente a la adversidad (Puvimanasinghe et al., 2014), lo que explicaría el hecho de que la religiosidad tenga un efecto moderador sobre el estrés (Bentley et al., 2014) e, incluso, sumada al apoyo social, reduzca los sintomas negativos de la migración (Finklestein et al., 2012).

Otra estrategia comúnmente mencionada fue pensar en el bienestar de la familia, por ejemplo en las posibles mejoras de condiciones de vida, formas de ayudarlos y garantizar su bienestar. Este mecanismo coincide con estudios previos (Aref y Tummala-Narra,2015; Puvimanasinghe et al., 2014), que resaltan su importancia como fortaleza en el proceso de migración (Aref y Tummala-Narra,2015). Asimismo, pensamientos de bienestar y gratitud podrían motivar la realización de conductas de colaboracionismo y ayuda a otros ( $\mathrm{Pu}-$ vimanasinghe et al., 2014).

La búsqueda activa de soluciones también fue resaltada por los participantes, la que podría asociarse a la resolución de problemas, como un intento de modificación de las situaciones que generan estrés (Tobin et al., 1989; Cano et al., 2007). Este tipo de estrategia podría ayudar a migrantes y refugiados a hacer frente a situaciones adversas en su proceso de adaptación (Walsh, 2004), aunque no necesariamente disminuye el malestar psicológico (Huits et al., 2012; Villacieros, Berástegui y Aza, 2016).

En contraste, algunos entrevistados identificaron las estrategias de afrontamiento por evitación, que han sido muy discutidas en la literatura (Finklestein et al., 2012). De acuerdo con un estudio con refugiados etíopes en Israel, la evitación o pasividad es una estrategia poco frecuente, que puede ser considerada desadaptada o rechazada en el país receptor, pero puede encajar mejor con algunas características culturales (Finklestein et al., 2012).

Se mencionó también que creer en las propias capacidades es una estrategia de afrontamiento útil ante la adversidad, de manera 
similar a otros estudios con población refugiada y solicitante de asilo (Ai et al., 2007; Bentley et al., 2014; Clarke y Border, 2014; Rae, 2016). Esta estrategia se puede reflejar en pensamientos de autovaloración utilizados por refugiados somalíes asentados en Inglaterra (Rae, 2016); o a situarse como protagonista valioso de la propia narrativa, lo que fue mencionado por refugiados procedentes de Liberia en Estados Unidos (Bentley et al., 2014). Adicionalmente, tener pensamientos positivos acerca de uno mismo y el futuro, matizando que estos esten ajustados a la realidad, puede ser un mecanismo útil para el proceso de adaptación, de acuerdo a refugiados kosovares asentados en Estados Unidos realidad (Ai et al., 2007).

Asimismo, los entrevistados señalaron que buscaron apoyo de otras personales, principalmente de su familia y amigos. La búsqueda de apoyo social como estrategia de afrontamiento ante el estrés ha sido ampliamente demostrada en diversos contextos de asilo (Aref y Tummala-Narra, 2015; Finklestein, Laufer y Solomon, 2012; Goodman, 2004; Guribye, 2011; Huijts, et al., 2012; Puvimanasinghe et al, 2014; Renner, Laireiter y Maier, 2012; Torres et al. 2017). Estudios previos mostraron que el apoyo de comunidades de origen de personas desplazadas funcionó como familias sustitutas brindando protección espontánea (Guribye, 2011) y que personas con altos niveles de apoyo social tenían bajos niveles de estrés (Finklestein et al., 2012). Así, la búsqueda activa de apoyo parece estar relacionada mejores niveles de calidad de vida (Huijts et al., 2012), reforzando la idea de que el apoyo social es un factor que ayuda a regular el efecto negativo de diversos estresores en el proceso de adaptación (Finch y Vega, 2003; Hovey 1999).

Finalmente, se señaló el uso de la expresión y comunicación de emociones como un mecanismo aplicado a diferentes estresores en el proceso de aculturación o a la suma de estos. De acuerdo con un estudio con refugiados asentados en Estados Unidos procedentes de distintos países como Somalia, Iraq, Sudan y Vietnam entre otros, "hablar de lo ocurrido" y escucharse unos a otros es una de sus fortalezas importante en el proceso de adaptación (Boucher, 2009).

\section{CONCLUSIONES:}

El estudio cualitativo en base a entrevistas con 22 de refugiados y solicitantes de asilo asentados en Lima (Perú) permitió identificar 
una amplia diversidad de estresores y estrategias de afrontamiento asociadas a este proceso, así como comprender la percepción de los participantes sobre estos.

El estrés por aculturación se manifestó en diversos estresores asociados a tres áreas: la falta de derechos y condiciones de vida adecuadas - como el limitado acceso a un trabajo digno, servicios básicos y vivienda-, las dificultades para relacionarse con las personas del país receptor - debido a la dificultad para adaptarse a las costumbres locales y los procesos de discriminación y rechazo, incluso por parte de la policía- y las dificultades familiares — relacionadas a problemas específicos de familia y la separación de esta por la migración.

Si bien no se tenía el objetivo de explorar diferencias por nacionalidad, se encontró que la población colombiana reportó con mayor recurrencia experiencias de discriminación por parte de la población local. Se recomienda realizar estudios que permitan explorar si hay diferencias en la discriminación u otros estresores debido a la nacionalidad.

Se utilizaron diversas estrategias de afrontamiento, como llevar una vida espiritual, pensar en el bienestar de su familia, creer en las propias capacidades, expresar emociones, la búsqueda activa de soluciones y de apoyo social y evitar problemas. Por tanto, se concluye que los participantes necesitan utilizar diferentes estrategias para hacer frente a la diversidad de estresores, las que incluyen tanto estrategias activas - centradas en la realización de acciones concretas para superar la adversidad, buscar apoyo o solucionar problemascomo cognitivas - para dar sentido a las experiencias que viven o hacer nuevas interpretaciones de estas.

Las principales limitaciones encontradas en este estudio fueron de corte metodológico. Una primera limitación es la posible deseabilidad social en las entrevistas, puesto que las investigadoras podían ser relacionadas a una organización de apoyo a refugiados en Lima que ayudó a contactar a los participantes del estudio. Además, la nacionalidad de las entrevistadoras - una de origen peruano y otra español- podría haber alterado los discursos debido a prejuicios sobre lo que el receptor de la comunicación va a entender, pensar o el miedo a ser juzgado. Una segunda limitación se refiere al acceso a la diversidad de población de refugiados y solicitantes de asilo en el Perú. Las entrevistas solo pudieron ser realizadas en español, por lo que personas de otras nacionalidades que no hablaban el idioma no pudieron ser entrevistados. Asimismo, se contactó a los 
participantes en función de la base de datos de la organización antes mencionada, por lo que personas que cumplían con los criterios de inclusión pero no contactaron a dicha organización no pudieron ser consideradas en el estudio.

A pesar de las limitaciones mencionadas, este estudio aporta a una mayor comprensión de los diversos estresores y estrategias de afrontamiento en el proceso de aculturación de personas latinas que migran forzosamente, que puede ser tomada en cuenta por organizaciones públicas y privadas para desarrollar y mejorar estrategias de intervención y políticas públicas que faciliten su proceso de acogida y adaptación en la región.

Asimismo, el uso de una metodología cualitativa ha permitido acercarse con mayor detalle a la realidad que viven las personas refugiadas y solicitantes de asilo en su proceso de adaptación. Este acercamiento aporta a la comprensión del proceso de estrés por aculturación, lo que también podría servir como base para el desarrollo de futuros estudios cualitativos o cuantitativos sobre el tema.

\section{REFERENCIAS BIBLIOGRÁFICAS}

Abubakar, I., Aldridge, R., Devakumar, D., Orcutt, M., Burns, R., Barreto, M. (...), Zimmerman, C. (2018). The UCL-Lancet Commission on Migration and Health: the health of a world on the move. The Lancet, 392. doi: 10.1016/S0140-6736(18)32114-7

Achotegui, J. (2008). Duelo migratorio extremo: el síndrome del inmigrante con estrés crónico y múltiple (Síndrome de Ulises). Avances en salud mental relacional, 7(1), 15-25. Recuperado de https://psiquiatria.com/ bibliopsiquis/migracion-y-crisis-el-sindrome-del-inmigrante-con-estrescronico-y-multiple-sindrome-de-ulises

ACNUR. (2014). Plan de Acción de Brasil: América Latina y el Caribe adoptan una hoja de ruta común para responder a las nuevas tendencias del desplazamiento y poner el fin a la apatridia. Recuperado de: https://www.acnur. org/5b5100c04.pdf

ACNUR. (2016). Tendencias globales. Desplazamiento forzado en 2015. Forzados a Huir. Recuperado de http://www.acnur.org/fileadmin/Documentos/ Publicaciones/2016/10627.pdf?view $=1$.

ACNUR. (2017). Tendencias Globales. Desplazamiento Forzado en 2016. Recuperado de https://www.acnur.org/5ab1316b4.pdf

ACNUR. (2018). Tendencias Globales. Desplazamiento Forzado en 2017. Recuperado de https://www.acnur.org/es-es/stats/globaltrends/5b2956a04/ tendencias-globales-desplazamiento-forzado-en-2017.html 
Ai, A., Tice, T., Whitsett, D., y Ishisaka, T. (2007). Posttraumatic symptoms and growth of Kosovar war refugees: The influence of hope and cognitive coping. The Journal of Positive Psychology, 2, 55-65. doi: $10.1080 / 17439760601069341$

Aref, I., y Tummala-Narra, P. (2015). Psychotherapy withrefugees: Emerging paradigm. Journal of Loss and Trauma, 20, 449-467. doi: HYPERLINK "https:// doi.org/10.1080/15325024.2014.949145” 10.1080/15325024.2014.949145

Bencek, D., y Strasheim, J. (2016). Refugees welcome? A dataset on antirefugee violence in Germany. Research and Politics, 3(4), 1-11. doi: $10.1177 / 2053168016679590$

Bentley, J., Ahmad, Z., y Thoburn, J. (2014). Religiosity and posttraumatic stress in a simple of East African refugees. Mental Health, Religion and Culture, 17 (2), 185-195. doi: HYPERLINK “https://doi.org/10.1080/1367 4676.2013.784899” 10.1080/13674676.2013.784899

Berganza, I. (2016). Ciudadanía migrante. Rutas, costos y dinámicas de los flujos mixtos en tránsito por Perú. Lima: Universidad Antonio Ruiz de Montoya, Encuentros SJS

Berry, J. (2005). Acculturation: living succesfully in two cultures. International Journal of Intercultural Relations, 29 (6), 697-712. doi: HYPERLINK "https://doi.org/10.1016/j.ijintrel.2005.07.013" \t “_blank” \o "Persistent link using digital object identifier” 10.1016/j.ijintrel.2005.07.013

Bhugra, D. (2004). Migration and mental health. Acta Psychiatri Scand, 109(4), 243-258. Recuperado de https:/www.academia.edu/13738713/ Migration_and_mental_health

Bonnano, G. E. (2010). Weighing the costs of disaster: consequences, risks and resilience in individuals, families and communities. Psychological Science in the Public Interest, 11(1), 1-49. doi: 10.1177/1529100610387086

Boucher, M. (2009). Finding resiliency, standing tall: Exploring trauma, hardship, and healing with refugees. The International Journal of $\mathrm{Na}$ rrative Therapy and Community Work, 4, 44-51. Recuperado de https:// dulwichcentre.com.au/product/finding-resiliency-standing-tall-exploring-trauma-hardship-and-healing-with-refugees-michael-boucher/

Cabrerizo, P., y Villacieros, I. (2017). Refugiados en Lima. Características sociales, medios de vida y percepción sobre el estrés de refugiados y solicitantes de asilo en Lima-Perú. Lima: Universidad Antonio Ruiz de Montoya, ACNUR, Encuentros Servicio Jesuita de la Solidaridad.

Cano, F., Rodríguez, L., y García, J. (2007). Spanish version of the Coping Strategies Inventory. Actas españolas de psiquiatría, 35(1), 29-39. Recuperado de https://www.ncbi.nlm.nih.gov/pubmed/17323223

CCPM, Migraciones, C. C. y Acnur. (2013). Diagnostico participativo con refugiados/as y solicitantes de asilo en Perú. Lima: ACNUR.

Clarke, L., y Border, L. (2014). "You got to apply seriousnees": A phenomenological inquiri of Liberian refugees coping. Journal of Counselling and Development, 92(3), 294-303. doi: HYPERLINK "https://doi.org/10.1002/ j.1556-6676.2014.00157.x” 10.1002/j.1556-6676.2014.00157.x 
De Luca, S., Bobowik, M., y Basabe, N. (2011). Adaptación sociocultural de inmigrantes brasileños en el País Vasco: Bienestar y aculturación. Revista de Psicología Social, 26(2), 275-294. doi: 10.1174/021347411795448983

De Luca, S., y Telletxea, S. (2017). Choque y adaptación sociocultural una visión en espejo: vascos y brasileños. Universitas Psychologica, 16(5), 1-14. doi: 10.11144/Javeriana.upsy 16-5.casv

Finch, B., Hummer, R., Kolody, B., y Vega, W. (2001). The role of discrimination and acculturative stress in the physical health of Mexicanorigin adults. Hispanic Journal of Behavioral Sciences, 23, 399-429. doi: HYPERLINK "https://doi.org/10.1177\%2F0739986301234004" 10.1177/0739986301234004

Finch, B., y Vega, W. (2003). Acculturation stress, social support, and selfrated health among Latinos in California. Journal of Immigrant and $\mathrm{Mi}$ nority Health, 5, 109-117. doi: 10.1023/A:1023987717921

Finklestein, M., Laufer, A., y Solomon, Z. (2012). Coping strategies of Ethiopian immigrants in Israel: association with PTSD and dissociation. Scandinavian Journal of Psychology, 53(6), 490-498. doi: HYPERLINK "https://doi.org/10.1111/j.1467-9450.2012.00972.x" \t “_blank" 10.1111/j.1467-9450.2012.00972.x

Flick, U. (2015). El diseño de investigación cualitativa. Madrid: Morata.

Furnham, A., y Bochner, S. (1986). Culture shock: Psychological reactions to unfamiliar environments. London: Methuen.

Goodman, J. (2004). Coping with trauma and hardship among unaccompanied refugee youth from Sudan. Qualitative Health Research, 14(9), 11771196. doi: HYPERLINK “https://doi.org/10.1177/1049732304265923" \t “_blank” 10.1177/1049732304265923

Gunnar, M., y Quevedo, K. (2007). The Neurobiology of Stress and Development. The Annual Review of Psychology, 58, 145-173. doi: HYPERLINK "https://doi.org/10.1146/annurev.psych.58.110405.085605” \t “_blank" 10.1146/annurev.psych.58.110405.085605

Guribye, E. S. (2011). Communal proactive coping strategies among Tamil refugees in Norway: A case study in a naturalistic setting. International Journal of Mental Health Systems, 5(1), 9-21. doi: HYPERLINK "https://dx.doi. org/10.1186\%2F1752-4458-5-9” \t “pmc_ext” 10.1186/1752-4458-5-9

Haagen, J., Heidi, F., Jackie, J., Mooren, T., Knipscheer, J., y Kleber, R. (2017). Predicting post-traumactic stress disorder treatment response in refugees: Multilevel analysis. Bristish Journal of Clinical Psychology, 56(1), 69-83. doi: 10.1111/bjc.12121.

Hernández, R., Fernández-Collado, C., y Baptista, P. (2014). Metodología de la Investigación. Sexta Edición. México D. F.: McGraw Hill.

Horyniak, D., Higgs, P., Cogger, S., Dietze, P., y Bofu, T. (2016). Heavy alcohol consumption among marginalised African refugee Young people in Melbourne, Australia: motivations for drinking, experiences of alcoholrelated problems and strategies for managing drinking. Ethnicity and Health, 21(3), 284-299. doi: 10.1080/13557858.2015.1061105. 
Hovey, J., y King, C. (1996). Acculturative stress, depression, and suicidal ideation among immigrant and second-generation Latino adolescents. Journal of the American Academy of Child and Adolescent Psychiatry, 35, 1183-1192. doi: HYPERLINK "https://doi.org/10.1097/00004583199609000-00016” \t “_blank” 10.1097/00004583-199609000-00016

Hovey, J. (1999). Psychosocial predictors of acculturative stress in Central American immigrants. Journal of Immigrant Health, 1, 187-194. Recuperado de https://deepblue.lib.umich.edu/bitstream/handle/2027.42/44942/ 10903_2004_Article_412535.pdf? sequence $=1$ \&isAllowed $=y$

Hsieh, H., y Shannon, S. (2005). Three Approaches to Qualitative Content Analysis. Qualitative Health Research, 15(9), 1277-1288. doi: $10.1177 / 1049732305276687$

Huijts, I., Kleijn, W., Van Emmerik, A., Noordhof, A., y Smith, A. (2012). Dealing woth man-made trauma: The relationship between coping style, posttraumatic stress, and quality of life in resettled, traumatized refugees in the Netherlands. Journal of Traumatic Stress, 25 (1), 71-78. doi: $10.1002 /$ jts. 21665

INEI. (2017). Estadisticas de seguridad ciudadana. Informe técnico. Lima: INEI.

Lazarus, R., y Folkman, S. (1986). Estrés y Procesos Cognitivos. Barcelona: Springer Publishing.

Ley del Refugiado. Ley Núm. 27891. Congreso de la República del Perú. (2002)

Medicos Sin Fronteras (2016). Negleted trauma. Asylum seekers in Italy: an analysis of mental health distress and access to healthcare. Milán: Medecins sans frontiers.

Morrison, D. (2016). Being with uncertainty: A reflective account of a personal relationship with an asylum seeker/refugee. Counselling Psychology Review, 31 (2), 10-21.

Poortinga, Y. (1997). Towards Convergence? En J. P. Berry, Handbook of Cross-Cultural Psychology. Volumen 1: Theory and Methods. Massachusetts: Allyn and Bacon.

Puvimanasinghe, T., Denson, L., Augoustinos, M., y Somasundaram, D. (2014). Giving back to society what society gave us: altruism, coping, and meaning making by two refugee communities in South Australia. Australian Psychologist, 49 (5), 313-321. doi: HYPERLINK "https://doi. org/10.1111/ap.12065" 10.1111/ap.12065

Rae, S. (2016). Somali male refugees: perceptions of depression and helpseeking. Counselling Psychology Review, 31(2), 46-60. doi: 10.13140/ RG.2.2.29682.15049

Renner, W., Laireiter, A., y Maier, M. (2012). Social support as a moderator of acculturatuve stress among refugees and asylum seekers. Social Behaviour and Personality: an international journal, 40(1), 129-146. doi: HYPERLINK “https://doi.org/10.2224/sbp.2012.40.1.129” 10.2224/sbp.2012.40.1.129

Rubio, P. (2012). La Protección Internacional de Refugiados en Perú: Ley 27.891 y su reglamento. En M. Lettieri, Protección internacional de 
refugiados en el Sur de Sudamérica (pp.443-480). Buenos Aires: Ediciones UNLa.

Seglem, K., Oppedal, B., y Roysamb, E. (2014). Daily hassles and coping dispositions as predictors of psychological adjustment: A comparative study of young unaccompanied refugees and youth in the resettlement country. International Journal of behavioral Development, 38(3), 293303. doi: HYPERLINK “https://doi.org/10.1177\%2F0165025414520807” 10.1177/0165025414520807

Séiner, K. (2014). Evaluación de medios de vida sostenibles de refugiados y solicitantes de asilo en Lima (Perú). Lima: Comisión Católica de Migración, Comisión Especial para los Refugiados, ACNUR.

Skinner, E., y Zimmer-Gembeck, M. (2007). The development of Coping. Annual Review of Psychology, 58, 119-144. doi: HYPERLINK "https://doi. org/10.1146/annurev.psych.58.110405.085705” \t “_blank” 10.1146/annurev.psych.58.110405.085705

Torres Fernández, I., Pereira, S., Aicart, J., y Salas, G. (2018). Cruzando Fronteras Internacionales en Búsqueda de una Vida Mejor: Examinando el Impacto Psicológico de la Experiencia Migratoria. Universitas Psychologica, 16(5), 1-15. doi: HYPERLINK "https://doi.org/10.11144/Javeriana. upsy16-5.cibs” 10.11144/Javeriana.upsy16-5.cibs

Urzúa M. A., Basabe, N., Echeverry, M., y Gibbons, J. (2017). Editorial. Universitas Psychologica, 16(5), 1-3. Recuperado de: https://revistas.javeriana.edu.co/index.php/revPsycho/article/view/21073

Urzúa M. A., Basabe, N., Pizarro, J., y Ferrer, R. (2017). Afrontamiento del estrés por aculturación: inmigrantes latinos en Chile. Universitas Psychologica, 16(5), 1-13. doi: 10.11144/Javeriana.upsy16-5.aeai

Villacieros, I., Berástegui, A., y Aza, G. (2016). Resiliencia familiar: un acercamiento al fenómeno de la triple frontera Perú, Bolivia, Chile, desde la perspectiva de los adolescentes. Madrid: Universidad Pontificia de Comillas. Recuperado de http://hdl.handle.net/11531/18375.

Ward, C., y Kennedy, A. (1999). The measurement of sociocultural adaptation. International Journal of Intercultural Relations, 23, 659-678. doi: 10.1016/S0147-1767(99)00014-0

Walsh, F. (2004). Resiliencia familiar. Estrategias para su fortalecimiento. Buenos Aires: Amorrortu.

Zarza, M., y Sobrino, M. (2007). Estrés de adaptación sociocultural en inmigrantes latinoamericanos residentes en Estados Unidos vs. España: Una revisión bibliográfica. Anales de Psicología, 23, 72-84. Recuperado de https://www.redalyc.org/html/167/16723110/

Zlobina, A., Basabe, N., y Páez, D. (2008). Las estrategias de aculturación de los inmigrantes: su significado psicológico. Revista de Psicología Social, 23(2), 143-150. doi: 10.1174/021347408784135760 